\title{
Shear Strength Prediction of FRP-reinforced Concrete Beams Using an Extreme Gradient Boosting Framework
}

\author{
Ali Kaveh $^{1 *}$, Seyed Mohammad Javadi', Roya Mahdipour Moghanni ${ }^{1}$ \\ ${ }^{1}$ Centre of Excellence for Fundamental Studies in Structural Engineering, Iran University of Science and Technology, Tehran 13114- \\ 16846, Iran \\ * Corresponding author, e-mail: alikaveh@iust.ac.ir
}

Received: 07 July 2021, Accepted: 06 September 2021, Published online: 10 September 2021

\begin{abstract}
Despite the importance and accuracy of empirical models, most of the existing models are only accurate on the collected experimental data. Adding new data, or even considering noise or variance in the data leads to loss of model accuracy. The objective of this paper is to alleviate overfitting and develop a more accurate and reliable alternative method using a decision-tree-based ensemble Machine Learning algorithm that uses a gradient boosting framework for the prediction of the ultimate shear strength of FRP-reinforced concrete beams without stirrups. To enhance the robustness of the results, make full use of training samples (without the validation set), and alleviate the randomness in selecting test samples, the K-Fold Cross Validation method is employed. Using a dataset including 205 samples, results show that the extreme gradient boosting framework (XGBoost) providing better prediction. In fact, XGBoost results have higher precision and higher generalization in comparison with the empirical equations, the current design codes of practice, Least Absolute Shrinkage and Selection Operator model (LASSO), and Random Forest model (RF).
\end{abstract}

Keywords

XGBoost, shear strength prediction, FRP, LASSO, Random Forest, Machine Learning

\section{Introduction}

The use of fiber-reinforced polymer (FRP) composites in strengthening reinforced concrete beams have been widely utilized for external flexural or shear reinforcement in construction. These materials are used as an alternative material for producing reinforcing bars. Some FRPs are non-conductive and non-corrosive helping durability in aggressive environments. Due to their mechanical properties including high longitudinal tensile strength and high fatigue endurance, and lightweight, in recent years, a large number of experimental tests have been conducted by researchers to determine the ultimate strength of reinforced concrete beams reinforced by FRPs.

The shear strength of FRP-reinforced concrete beams may differ from that of members reinforced with steel due to the difference in mechanical properties between FRP and steel reinforcement [1]. Shear failures were reported in several flexure tests for FRP-reinforced concrete beams including Michaluk et al. [2].

Razaqpur et al. [3] tested seven beams in bending to determine the concrete contribution to their shear resistance; they concluded that the ACI recommendations are extremely conservative whereas the Canadian and Japan Society of Civil Engineers (JSCF) recommendations, albeit still conservative, are in closer agreement with the experimental data. The same conclusion is mentioned about ACI recommendations in [4]. Ashour [5] reported an inconsistency for the shear capacity calculation of GFRP-reinforced concrete beams between experimental results with those mentioned in ACI 318-99.

From a mechanics-based segmental approach, Zhang et al. [6] derived a generic closed-form solution for quantifying the shear capacity of RC beams and one-way slabs without stirrups.

Nowadays, Metaheuristics are used as a powerful tool for engineering prediction problems [7-10].

Some researchers used Artificial Neural Network (ANN) to solve prediction problems. For example, Kaveh et al. [11] used a deep learning approach for predicting the ultimate buckling load of variable-stiffness composite cylinders.

Because of the advancement of Machine Learning Regression methods (MLRs), in this paper, shear strength prediction of FRP-reinforced concrete beams has been 
investigated using the most recent powerful MLRs including Least Absolute Shrinkage and Selection Operator (LASSO), Random Forest (RF), and extreme gradient boosting framework (XGBoost).

The remainder of this article is organized into five sections, as follows. Section 2 presents the basics of the Shear strength of FRP-RC beams and the dataset developed in this research. Section 3 is devoted to introducing the MLRs. This section includes a brief review of the K-Fold Cross Validation method. The results and discussion of the empirical equations, the current design codes of practice, and MLR results are presented in Sections 4. Finally, the conclusions are drawn in Section 5.

\section{Shear strength of FRP-RC beams}

Cracked reinforced concrete members resist the applied shear stresses by the following five mechanisms [12]:

- Shear stresses in uncracked concrete i.e., the flexural compression zone;

- Interface shear transfer (aggregate interlock/crack friction)

- Dowel action of the longitudinal reinforcing bars

- Arch action
- Residual tensile stresses transmitted directly across cracks

Researchers proposed several equations based on various experimental studies and the principles of structural mechanics. A summary of some shear design equations for FRP-reinforced members is provided in Table 1. As these equations have been empirically derived there are still gaps in selecting the main parameters affecting Vcf.

In this study, we utilized 24 datasets including 205 FRP reinforced concrete beams to benchmark our approach. These datasets are summarized in Table 2.

The dataset consists of 8 attributes including 7 input data features and 1 output. Table 3 and Fig. 1 present the summary of the statistical range of features and their corresponding correlations, respectively. In this figure relationships between random variables are provided. It can be inferred that the width of the web and the effective depth of the cross-section have the highest correlations with shear capacity.

Furthermore, the distribution of the parameters and corresponding shear strength included in the database is shown in Fig. 2.

Table 1 Shear design formulas for FRP-reinforced concrete beam without shear reinforcement

\begin{tabular}{|c|c|c|}
\hline Author(s)/Code & Formula & Note \\
\hline ACI440.1R-15 [13] & $V_{c f}=\frac{2}{5} \sqrt{f_{c}^{\prime}} b_{w} c$ & $\begin{array}{c}c=k d \\
k=\sqrt{2 \rho_{f} n+\left(\rho_{f} n\right)^{2}}-\rho_{f} n \\
n=\frac{E_{f}}{E_{c}}\end{array}$ \\
\hline CSA S806-02 [14] & $\begin{array}{c}\text { For } d \leq 3 \mathrm{~mm} \\
V_{c f_{1}}=0.35 \lambda\left(f_{c}^{\prime} \rho_{f} E_{f} \frac{V_{f}}{M_{f}} d\right)^{1 / 3} b_{w} d \\
\text { For } d>300 \mathrm{~mm}: V_{c f_{2}}=\frac{130}{1000+d} \lambda \sqrt{f_{c}^{\prime}} b_{w} d\end{array}$ & $\begin{array}{l}V_{c f 1(\min )}=0.1 \lambda \sqrt{f_{c}^{\prime} b_{w} d} \\
V_{c f 1(\max )}=0.2 \lambda \sqrt{f_{c}^{\prime} b_{w} d} \\
V_{c f 2(\max )}=0.08 \lambda \sqrt{f_{c}^{\prime} b_{w} d}\end{array}$ \\
\hline Tureyen and Frosch [15] & $V_{c f}=\frac{5}{12} k \sqrt{f_{c}^{\prime}} b_{w} d$ & $\begin{array}{c}k=\sqrt{2 \rho_{f} n+\left(\rho_{f} n\right)^{2}}-\rho_{f} n \\
n=\frac{E_{f}}{E_{c}}\end{array}$ \\
\hline El-Sayed et al. [1] & $V_{c f}=\left(\frac{\rho_{f} E_{f}}{90 \beta_{1} f_{c}^{\prime}}\right)^{\overline{3}}\left(\frac{\sqrt{f_{c}^{\prime}}}{6} b_{w} d\right) \leq \frac{\sqrt{f_{c}^{\prime}}}{6} b_{w} d$ & $\beta_{1}=0.85-0.05\left(\frac{f_{c}^{\prime}-28}{7}\right) \geq 0.65$ \\
\hline Alam and Hussein [16] & $V_{c f}=\frac{0.2 \lambda}{\left(\frac{a}{d}\right)^{2 / 3}}\left(\frac{\rho_{f} E_{f}}{d}\right)^{1 / 3} \sqrt{f_{c}^{\prime}} b_{w} d$ & $\begin{array}{c}V_{c(\min )}=\frac{0.1}{\left(\frac{a}{d}\right)} \lambda \sqrt{f_{c}^{\prime}} b_{w} d \\
V_{c(\max )}=0.2 \lambda \sqrt{f_{c}^{\prime}} b_{w} d\end{array}$ \\
\hline
\end{tabular}


Table 2 Database of 205 FRP reinforced concrete beams

\begin{tabular}{|c|c|c|c|c|}
\hline Reference & \multicolumn{4}{|c|}{ Specimen } \\
\hline Nagasaka et al. [17] & \multicolumn{4}{|c|}{ AN0090M, AN0090L } \\
\hline Nakamura and Higai [18] & \multicolumn{4}{|c|}{ G01, G02 } \\
\hline Zhao et al. [19] & \multicolumn{4}{|c|}{$1,2,3$} \\
\hline Duranovic et al. [20] & \multicolumn{4}{|c|}{ GB2, GB6 } \\
\hline Swamy and Aburawi [21] & \multicolumn{4}{|c|}{ F3-GF } \\
\hline Deitz et al. [22] & \multicolumn{4}{|c|}{ GFRP1, GFRP2, GFRP3, Hybrid1, Hybrid2 } \\
\hline Yost et al. [23] & \multicolumn{4}{|c|}{$\begin{array}{c}\text { 1FRPa, 1FRPb, 1FRPc, 2FRPa, 2FRPb, 2FRPc, 3FRPa, 3FRPb, 3FRPc, 4FRPa, 4FRPb, 4FRPc, 5FRPa, 5FRPb, } \\
\text { 5FRPc, 6FRPa, 6FRPb, 6FRPc }\end{array}$} \\
\hline Alkhrdaji et al. [24] & \multicolumn{4}{|c|}{ BM7, BM8, BM9 } \\
\hline Massam [25] & \multicolumn{4}{|c|}{$\mathrm{LB} / 8 / 0.5 / 0, \mathrm{LB} / 4 / 0.5 / 0, \mathrm{LB} / 2 / 0.5 / 0, \mathrm{LB} / 8 / 2 / 0, \mathrm{LB} / 4 / 2 / 0, \mathrm{LB} / 2 / 2 / 0$} \\
\hline Tureyen and Frosch [4] & \multicolumn{4}{|c|}{ V-G1-1, V-G2-1, V-A-1, V-G1-2, V-G2-2, V-A-2 } \\
\hline Tariq and Newhook [26] & \multicolumn{4}{|c|}{ G07N1, G07N2, G10N1, G10N2, G15N1, G15N2, C07N1, C07N2, C10N1, C10N2, C15N1, C15N2 } \\
\hline Gross et al. [27] & \multicolumn{4}{|c|}{$\begin{array}{l}\text { FRP-1a-26-NS, FRP-1b-26-NS, FRP-1c-26-NS, FRP-2a-26-NS, FRP-2b-26-NS, FRP-2c-26-NS, FRP-3a-36-NS, } \\
\text { FRP-3b-36-NS, FRP-3c-36-NS, FRP-4a-46-NS, FRP-4b-46-NS, FRP-4c-46-NS, FRP-5a-37-NS, FRP-5b-37-NS, } \\
\text { FRP-5c-37-NS, FRP-6a-37-NS, FRP-6b-37-NS, FRP-6c-37-NS }\end{array}$} \\
\hline Razaqpur et al. [3] & \multicolumn{4}{|c|}{$\mathrm{BR} 1, \mathrm{BR} 2 / \mathrm{BA} 2, \mathrm{BR} 3, \mathrm{BR} 4, \mathrm{BA} 1, \mathrm{BA} 3, \mathrm{BA} 4$} \\
\hline El-Sayed et al. [28] & \multicolumn{4}{|c|}{ S-C1, S-C2B, S-C3B, S-G1, S-G2, S-G2B, S-G3, S-G3B } \\
\hline Ashour [5] & \multicolumn{4}{|c|}{ Beam1, Beam3, Beam5 } \\
\hline El-Sayed et al. [29] & \multicolumn{4}{|c|}{$\mathrm{CN}-1, \mathrm{GN}-1, \mathrm{CN}-2, \mathrm{GN}-2, \mathrm{CN}-3$, GN-3 } \\
\hline Guadagnini et al. [30] & \multicolumn{4}{|c|}{ GB43, GB44, GB45 } \\
\hline Matta et al. [31] & \multicolumn{4}{|c|}{$\mathrm{S} 1-1, \mathrm{~S} 3-2, \mathrm{~S} 3-3, \mathrm{~S} 6-2, \mathrm{~S} 6-3, \mathrm{~S} 1 \mathrm{~B}-1, \mathrm{~S} 1 \mathrm{~B}-2$} \\
\hline Jang et al. [32] & \multicolumn{4}{|c|}{$\begin{array}{l}\text { C-1.5-R1-1-2, C-1.5-R2-1-2, C-1.5-R3-1-2, C-2.0-R1-1-2, C-2.0-R2-1-2, C-2.0-R3-1-2, C-2.5-R1-1-2, C-2.5-R2-1-2, } \\
\text { C-2.5-R3-1-2, C-3.5-R1-1-2, C-3.5-R2-1-2, C-3.5-R3-1-2, C-4.5-R1-1-2, C-4.5-R2-1-2, C-4.5-R3-1-2, G-1.5-R1-1-2, } \\
\text { G-1.5-R2-1-2, G-1.5-R3-1-2, G-2.0-R1-1-2, G-2.0-R2-1-2, G-2.0-R3-1-2, G-2.5-R1-1-2, G-2.5-R2-1-2, G-2.5-R3-1-2, } \\
\text { G-3.5-R1-1-2, G-3.5-R2-1-2, G-3.5-R3-1-2, G-4.5-R1-1-2, G-4.5-R2-1-2, G-4.5-R3-1-2 }\end{array}$} \\
\hline Bentz et al. [33] & \multicolumn{4}{|c|}{ M05-0, S05-0, M20-0, S20-0, 105-0, 120-0 } \\
\hline Olivito and Zuccarello [34] & \multicolumn{4}{|c|}{$\begin{array}{c}\text { SI-1, SI-2, SI-3, SI-4, SI-5, SII-1, SII-2, SII-3, SII-4, SII-5, SIII-1, SIII-2, SIII-3, SIII-4, SIII-5, SIV-1, SIV-2, SIV-3, } \\
\text { SIV-4, SIV-5 }\end{array}$} \\
\hline Abed et al. [35] & \multicolumn{4}{|c|}{ B1FRP, B2FRP, B3FRP, B4FRP, B5FRP, B6FRP, B7FRP } \\
\hline Alam and Hussein [16] & \multicolumn{4}{|c|}{$\begin{array}{c}\text { G-2.5, G-3.5, C-2.5, C-3.5, G-500, G-650, G-800, C-500, C-650, C-800, G-2.5-350, G-2.5-350, G-0.5-500, G-2.5-500, } \\
\text { C-0.5-350, C-2.5-350, C-0.5-500, C-2.5-500 }\end{array}$} \\
\hline Matta et al. [36] & \multicolumn{4}{|c|}{$\begin{array}{l}\text { S1-0.12-1A, S1-0.12-2B, S3-0.12-1A, S3-0.12-2A, S6-0.12-2A, S6-0.12-3A, S1-0.24-1A, S1-0.24-2B, S3-0.24-1B, } \\
\text { S3-0.24-2B, S6-0.24-1B, S6-0.24-2B }\end{array}$} \\
\hline Property & Minimum & Maximum & Mean & Standard deviation \\
\hline$b(\mathrm{~mm})$ & 114.00 & 1000.00 & 260.92 & 177.54 \\
\hline$d(\mathrm{~mm})$ & 146.00 & 938.00 & 286.27 & 169.28 \\
\hline ald & 1.00 & 6.50 & 3.59 & 1.23 \\
\hline$f_{c}^{\prime}(\mathrm{MPa})$ & 22.70 & 50.00 & 34.98 & 5.63 \\
\hline$\rho_{f r p}(\%)$ & 0.18 & 3.43 & 1.12 & 0.63 \\
\hline$F_{s y}(\mathrm{MPa})$ & 397.00 & 2250.00 & 1209.56 & 615.88 \\
\hline$E_{f}(\mathrm{GPa})$ & 22.70 & 30.40 & 26.47 & 1.59 \\
\hline$V_{\exp }(\mathrm{KN})$ & 12.50 & 232.00 & 64.81 & 51.60 \\
\hline
\end{tabular}




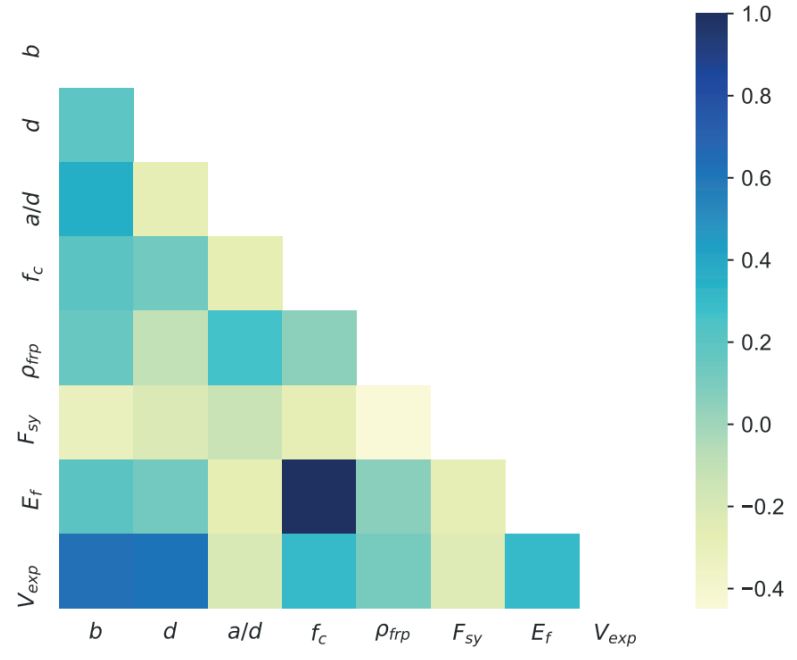

Fig. 1 Correlation of the features

\section{Machine Learning prediction}

\subsection{Least Absolute Shrinkage and Selection Operator} (LASSO)

LASSO [37] is an MLR analysis method. In this method, in order to avert overfitting, the linear model is trained with $\mathrm{L}_{1}$ prior as a regularizer. In other words, LASSO adds an absolute value of the magnitude of coefficient as a penalty term to the loss function. In this model, the optimization function defined as:

$$
\text { Loss function }=\sum_{i=1}^{n}\left(y_{i}-\left(\beta_{0}+\sum_{j=1}^{p} \beta_{j} x_{i j}\right)\right)^{2}+\lambda \sum_{j=1}^{p}\left|\beta_{j}\right| \text {, }
$$

where $x_{i j}$ is the training data and $y_{i}$ is the observation. In the above loss function, the first part is the residual sum of squares and the remaining is the sum of the absolute value of coefficients. In addition, $\lambda$ is the penalty parameter providing a trade-off between the first and second parts. lasso imposes an $\mathrm{L}_{1}$ penalty on the $\beta$. That is, lasso finds an assignment to $\beta_{0}$ and $\beta$ that minimize the loss function.

\subsection{Random Forest (RF)}

Random Forest regression as a supervised machine learning algorithm uses an ensemble learning method for prediction. The RF model for regression can be described in Algorithm 1.

An illustration of ensemble learning for RF is shown in Fig. 3. The RF algorithm is not biased and it improves stability and accuracy because of the combination of several trees. Further details of the RF algorithm can be found in [38].

\subsection{Extreme gradient boosting framework (XGBoost)}

$\mathrm{XGBoost}$ is an efficient implementation of gradient boosting that can be used for regression predictive modeling.

XGBoost as a gradient boosting decision tree adds models sequentially; however, random forest adds multiple predictors in parallel. It utilizes regularized learning and cache-aware block structure tree learning. This method is based on function approximation and optimizing specific loss functions expressed as follows [39]:

$\mathcal{L}^{t}=\sum_{i=1}^{n} l\left(y_{i}, \hat{y}_{i}^{(t-1)}+f_{t}\left(x_{i}\right)\right)+\Omega\left(f_{t}\right)$,

$\Omega(f)=\gamma T+\frac{1}{2} \lambda \omega^{2}$,

where $l$ is a differentiable convex loss function measuring the difference between the $\hat{y}_{i}$ and the $y_{i}$. The second term $\Omega$ penalizes the complexity of the model in order to prevent overfitting. $T$ is the number of leaves and $\omega$ is

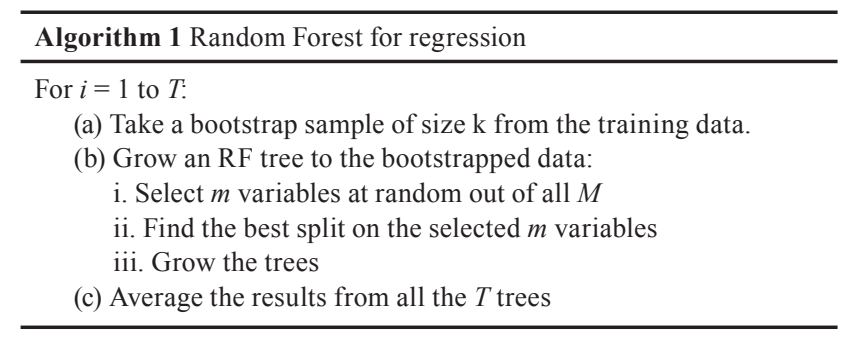

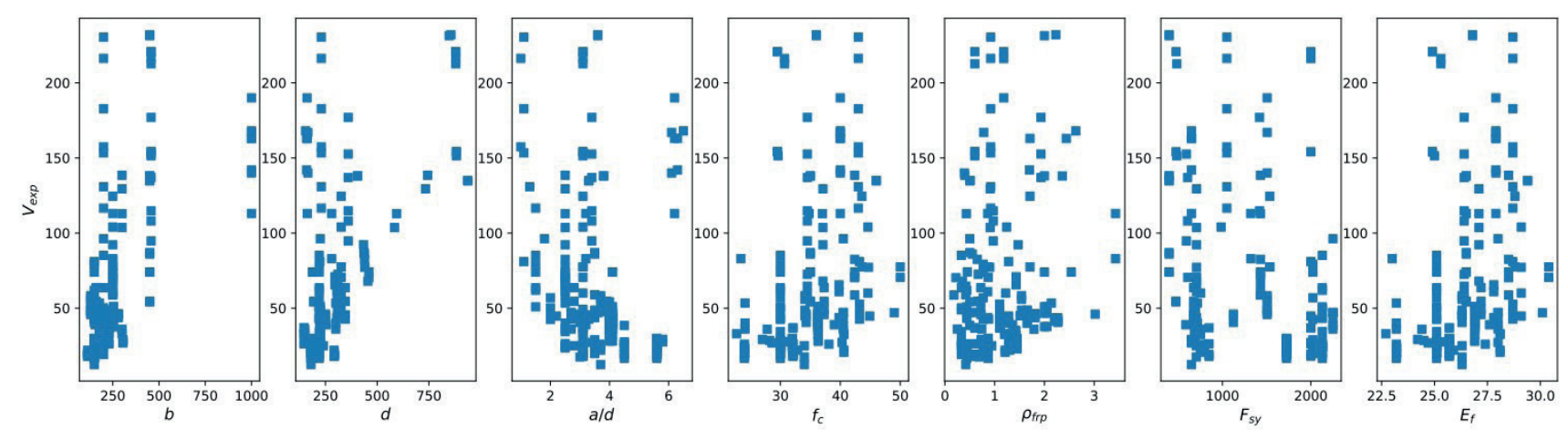

Fig. 2 The relationship between the seven input variables and the nominal shear strength provided by concrete in the data set 


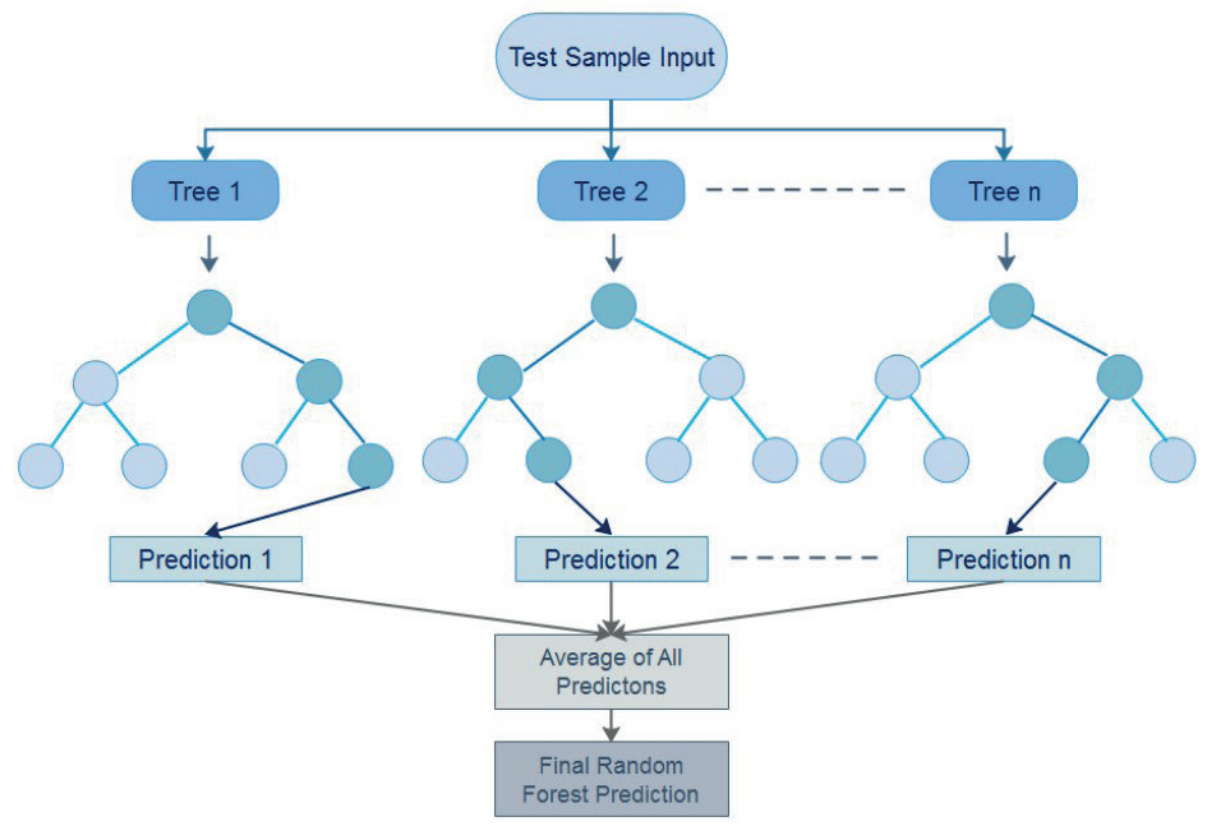

Fig. 3 Illustration of ensemble learning for random forest

the vector of scores on leaves. By using the second-order Taylor approximation, Eq. (2) can be expressed as follows:

$\mathcal{L}^{t}(q)=-\frac{1}{2} \sum_{j=1}^{T} \frac{\left(\sum_{i \in I_{j}} g_{i}\right)^{2}}{h_{i}+\lambda}+\gamma T$,

$g_{i}=\partial_{\hat{y}(t-1)} l\left(y_{i}, \hat{y}_{i}^{(t-1)}\right)$,

$h_{i}=\partial_{\hat{y}(t-1)}^{2} l\left(y_{i}, \hat{y}_{i}^{(t-1)}\right)$.

To avoid overfitting, XGBoost integrates multiple weak predictors rather than strong ones. XGBoost uses scalability in all scenarios and handles sparse data using a tree learning algorithm. Further details about this algorithm can be found in [39].

\subsection{K-Fold Cross-Validation}

In a supervised machine learning problem, holding out part of the data as a validation set is prevalent. However, to avoid overfitting and the need to make full use of samples that can be used for training the model, the K-Fold Cross Validation [40] is used in this paper. By applying this method, the validation set is no longer needed. Here, the data set is split into 10 folds. In the first iteration, the first fold is used to test the model and the remainder is used to train the model. This process is repeated until each fold of the 10 folds has been used as the testing set. Fig. 4 illustrates the general structure of the 10-Fold CrossValidation used in this investigation. The flowchart for the ML model is illustrated in Fig. 5.

\section{Results of Prediction models}

For our investigation, the entire dataset is divided into two parts, $80 \%$ for training and $20 \%$ for testing. In this paper, the width of the web, effective depth of cross-section, shear span to effective depth ratio, the specified compressive strength of concrete, FRP reinforcement ratio, modulus of elasticity of flexural FRP reinforcement, and yielding strength of the reinforcement have been taken as the input variables.

\subsection{Performance measures}

The results of the ML models are compared using the rootmean-square error (RMSE), mean absolute error (MAE), and R-squared (R2). Definitions of these statistical indicators are given as follows:

$$
\begin{aligned}
& \text { RMSE }=\sqrt{\frac{1}{n} \sum_{i=1}^{n}\left(y_{i}-\hat{y}_{i}\right)^{2},} \\
& M A E=\frac{1}{n} \sum_{i=1}^{n}\left|y_{i}-\hat{y}_{i}\right|, \\
& R^{2}=1-\frac{\sum_{i=1}^{n}\left(y_{i}-\hat{y}_{i}\right)^{2}}{\sum_{i=1}^{n}\left(y_{i}-\bar{y}\right)^{2}},
\end{aligned}
$$

where $N$ is the number of testing samples, $\hat{y}_{i}$ and the $y_{i}$ are the target and the prediction of the $I$-th sample, respectively; $\bar{y}$ is the average of the predicted outputs. 


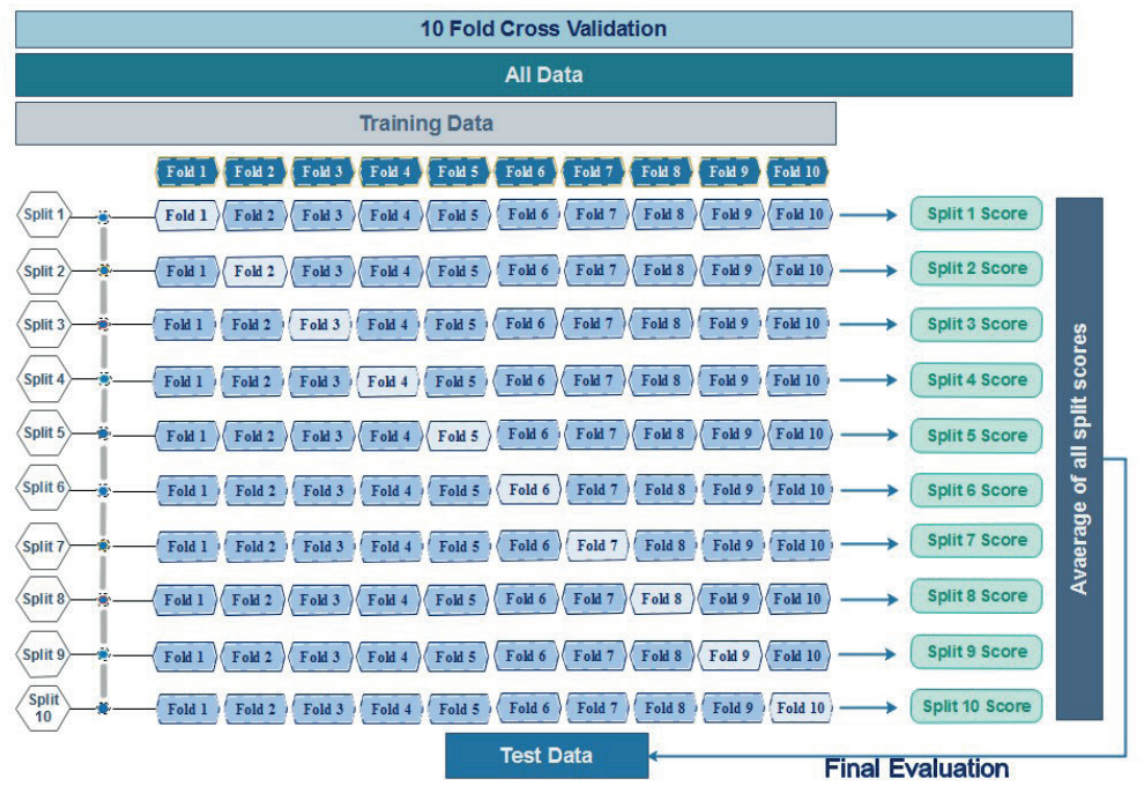

Fig. 4 Illustration of 10-Fold Cross-Validation

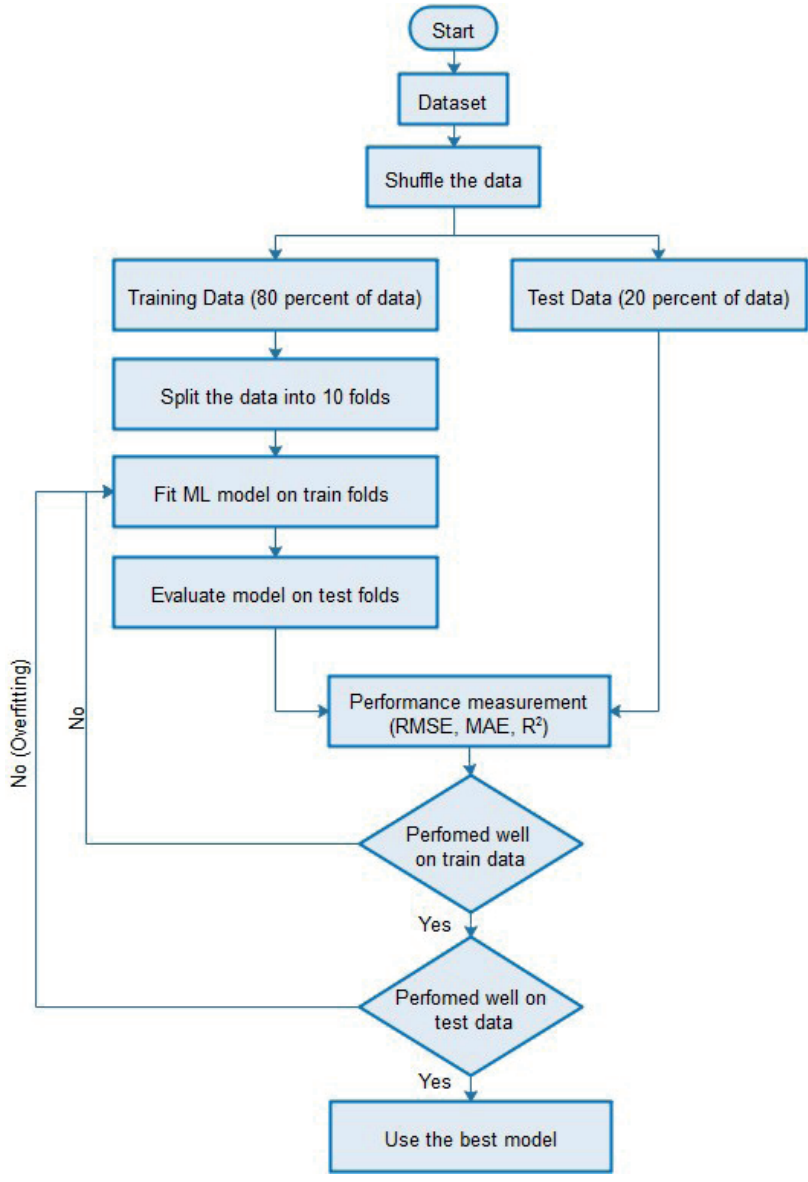

Fig. 5 Implementation of ML model

\subsection{Comparison with previous Modeling Approaches}

A feature importance analysis is performed for the XGBoost model to break down the seven input variables for the shear strength of FRP-reinforced concrete beams, and the results are shown in Fig. 6. As it can be seen, the four variables determined to have high feature importance, i.e., the width of the web, effective depth of cross-section, shear span to effective depth ratio, and specified compressive strength of concrete. In this analysis, the modulus of elasticity of flexural FRP reinforcement has the smallest relative importance.

Fig. 7 Shows the comparison of prediction models for shear capacity with experimental data. By comparing the experimental and the theoretical model for 40 test samples, it is inferred that current guidelines provide conservative values. On the other hand, the XGBoost and RF model outperforms LASSO and the other empirical models.

The values of the RMSE, $\mathrm{R}^{2}$, and MAE are presented in Fig. 8. Results indicate that the XGBoost predicts the experimental shear capacity relatively accurately. In addition, it can be inferred that XGBoost outperforms other MLR methods; on the basis of the RMSE and MAE, the

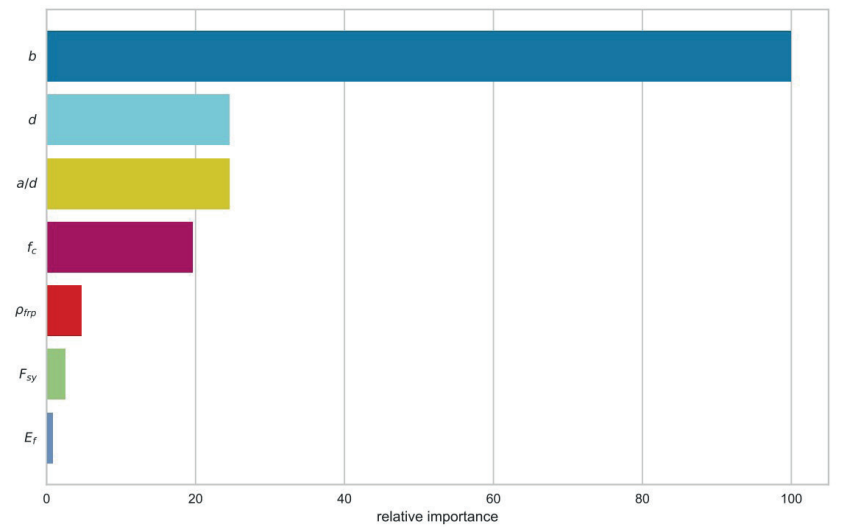

Fig. 6 Feature importance of the seven input variables using XGBoost 


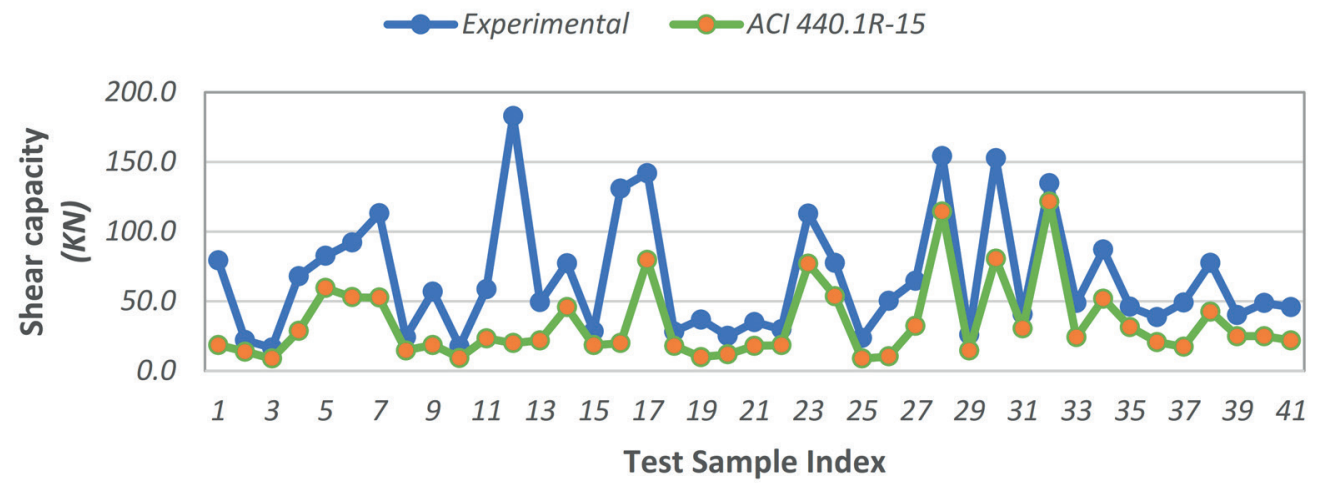

(a)

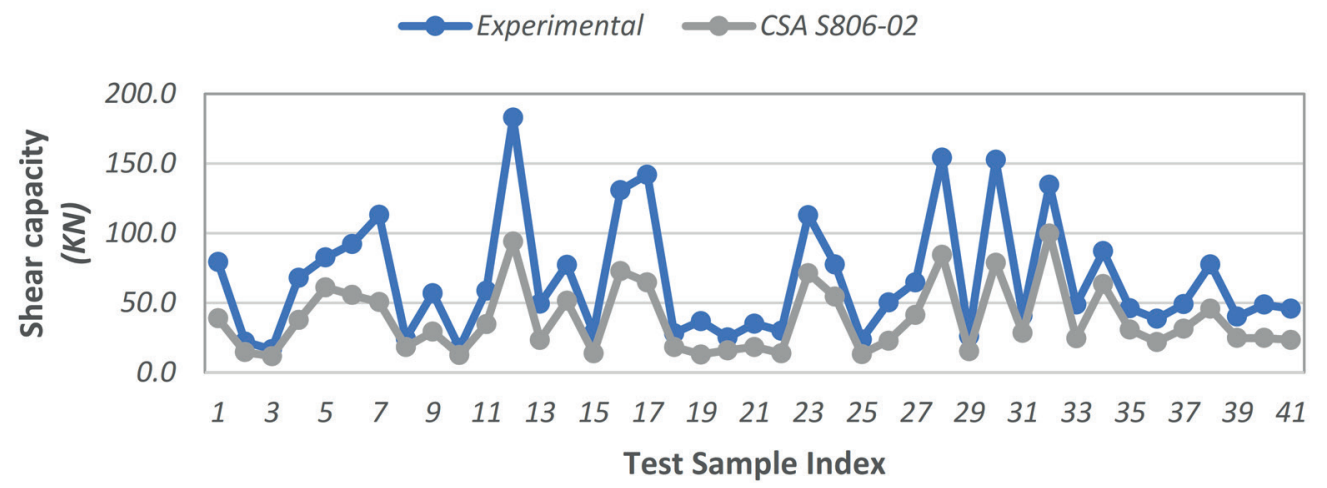

(b)

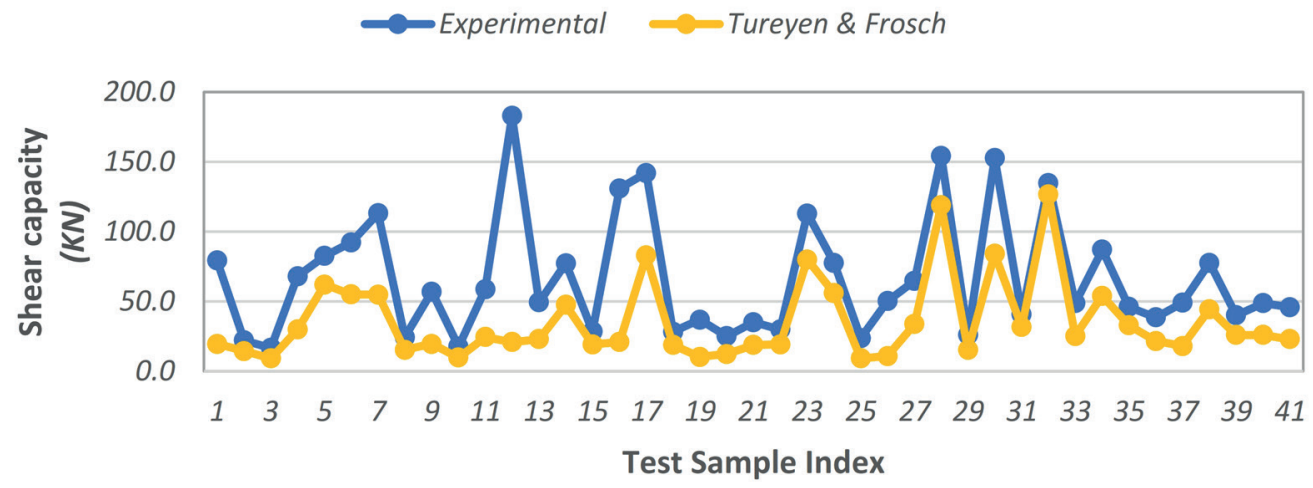

(c)

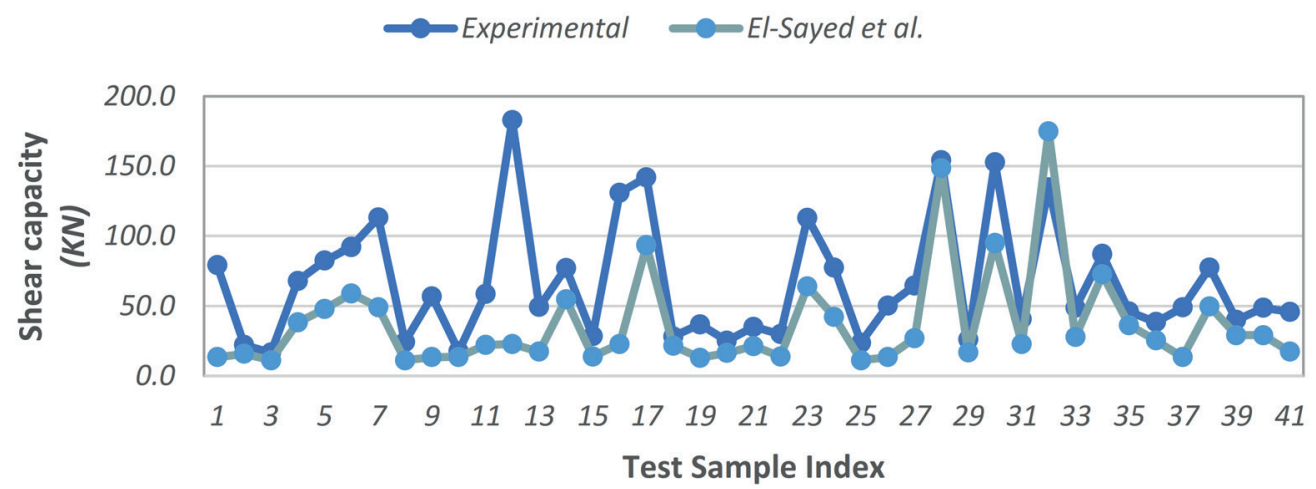

(d)

Fig. 7 Comparison of predicted shear capacity with experimental shear resistance (Figs. (a) to (d)) 


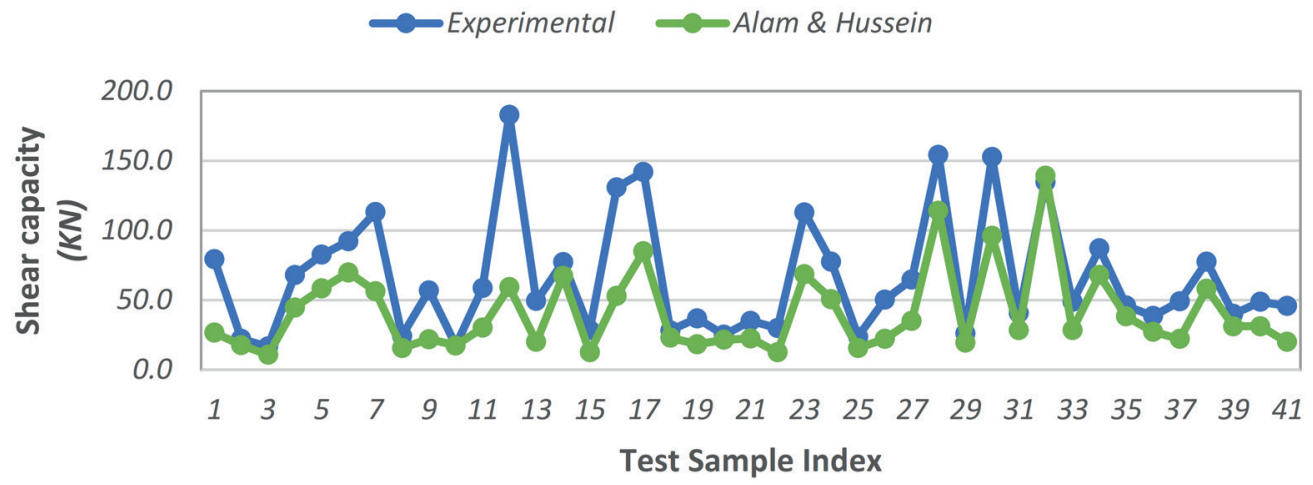

(e)

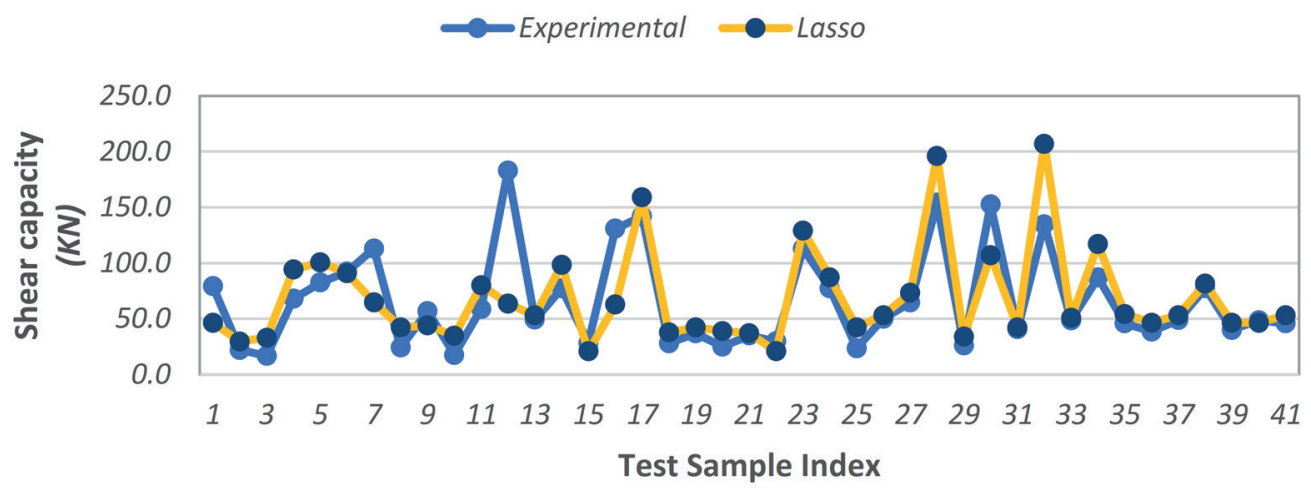

(f)

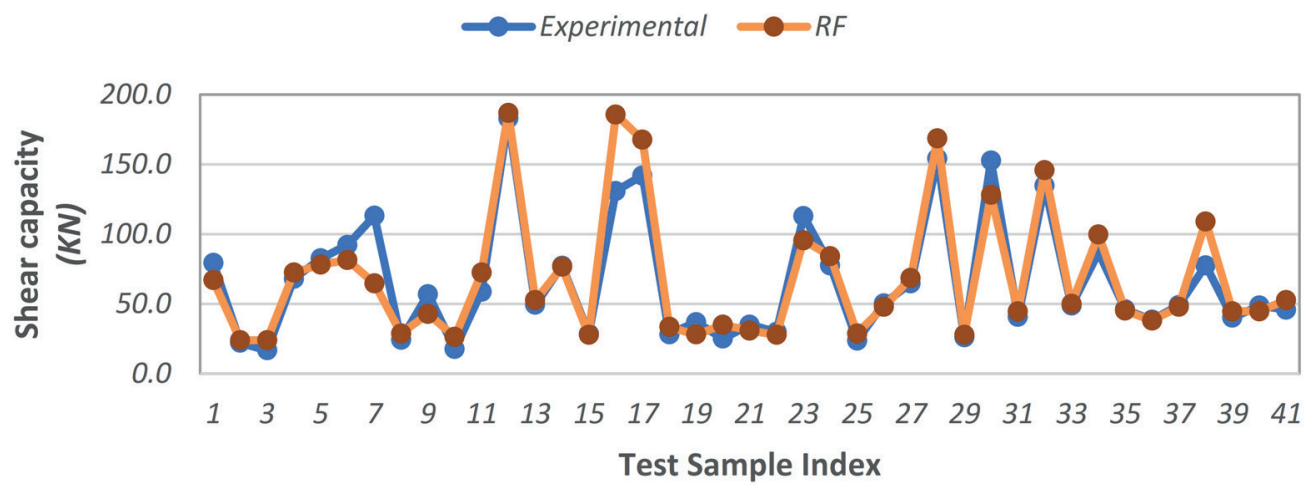

(g)

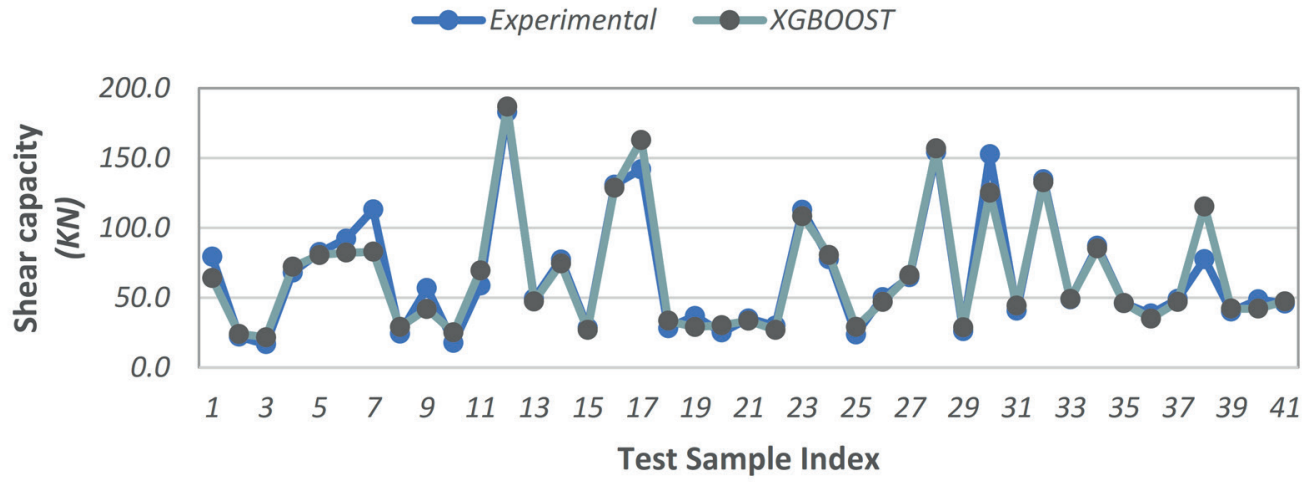

(h)

Fig. 7 Comparison of predicted shear capacity with experimental shear resistance (Figs. (e) to (h)) 


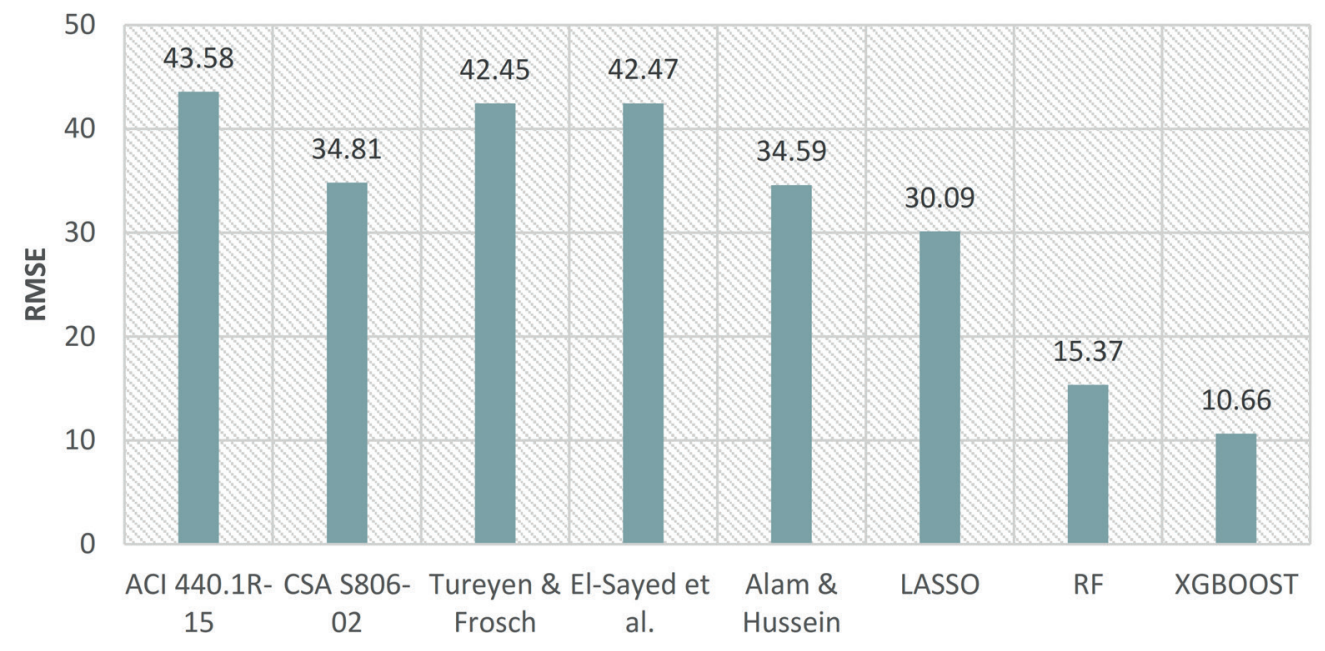

(a)

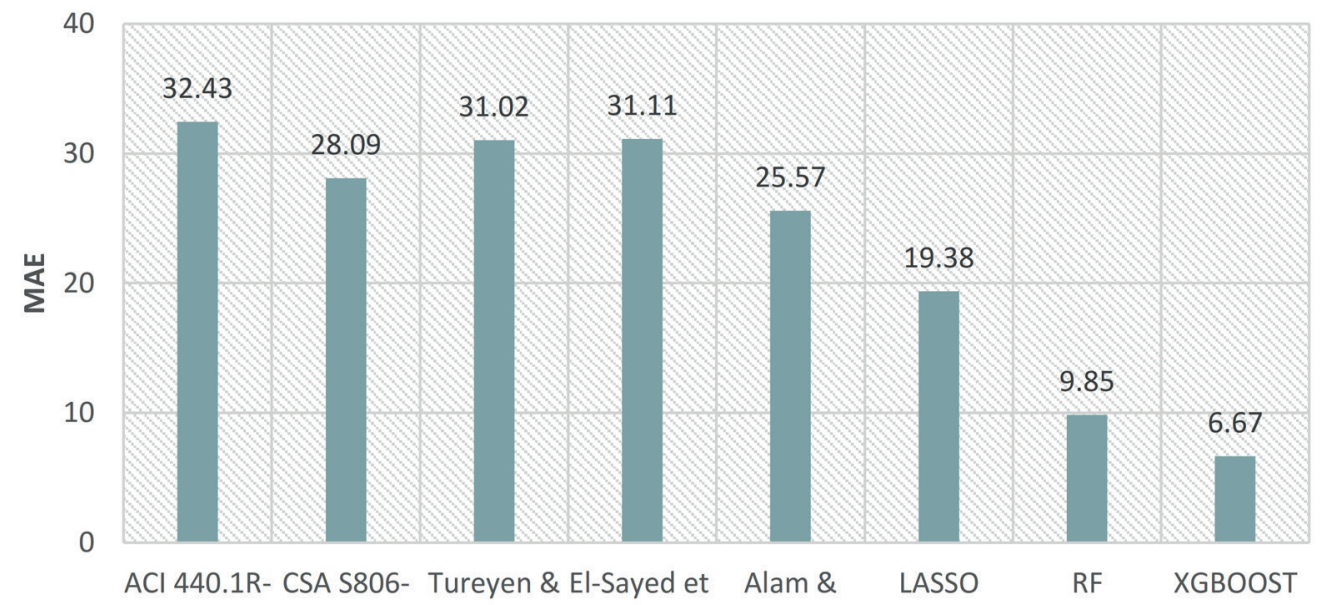
15
02
Frosch
al. Hussein

(b)

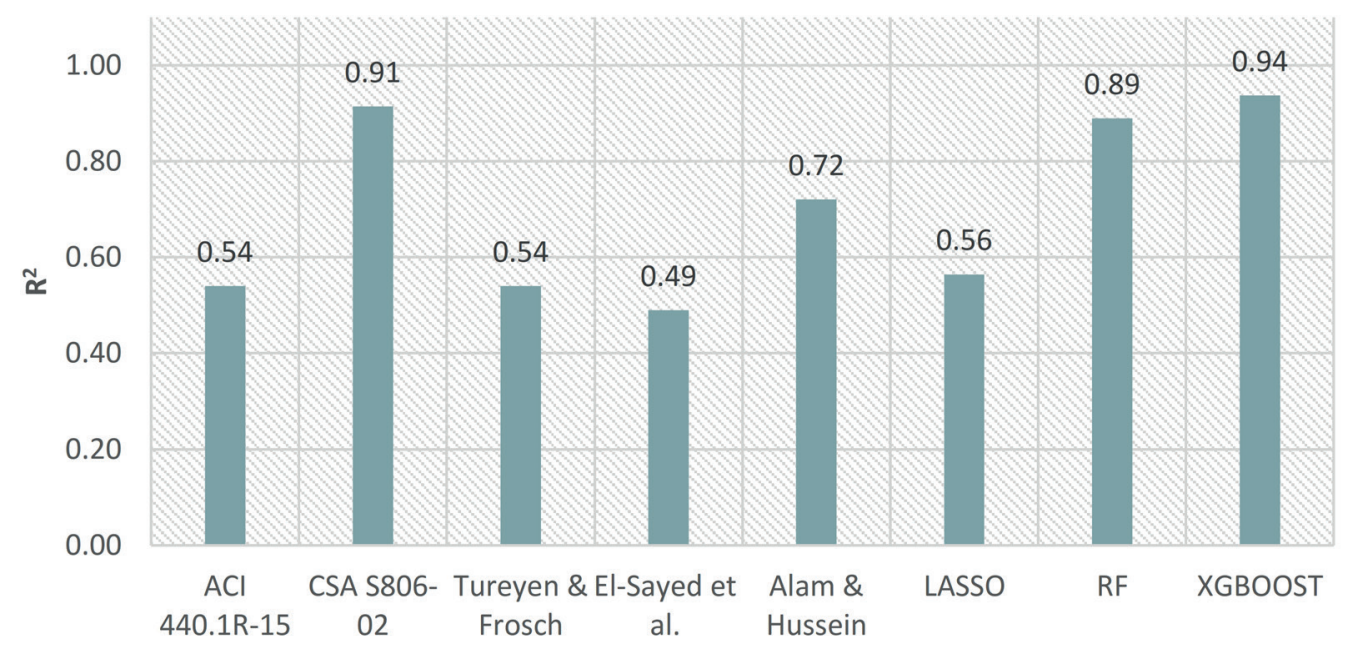

(c)

Fig. 8 Results comparison between all test samples for shear strength prediction of FRP-reinforced concrete beams: (a) RMSE; (b) MAE; (c) R ${ }^{2}$ 
XGBoost model obtains RMSE of $10.66 \mathrm{KN}$, and MAE of 6.67 KN which are lower than RF, LASSO, empirical equations, and the design codes of practice used in this paper.

The differences between the experimental values and the predicted values for the XGBoost model are shown in Fig. 9. The residuals plot shows the difference between residuals on the vertical axis and the predicted value on the horizontal axis. Due to the lack of sufficient experimental data, it can be inferred that regions with a shear strength of larger than are susceptible to more error.

\section{Conclusions}

The primary aim of this study is to use the ensemble learning framework to improve the shear strength prediction of FRPreinforced concrete beams without stirrups. A relatively large dataset with over 205 samples is collected from different research papers and used to train the predictive models.

The paper details the feasibility of using MLR methods including LASSO, RF, and XGBoost algorithm for prediction problems. The 10-Fold Cross-Validation technique is used to improve the robustness of the results, make full

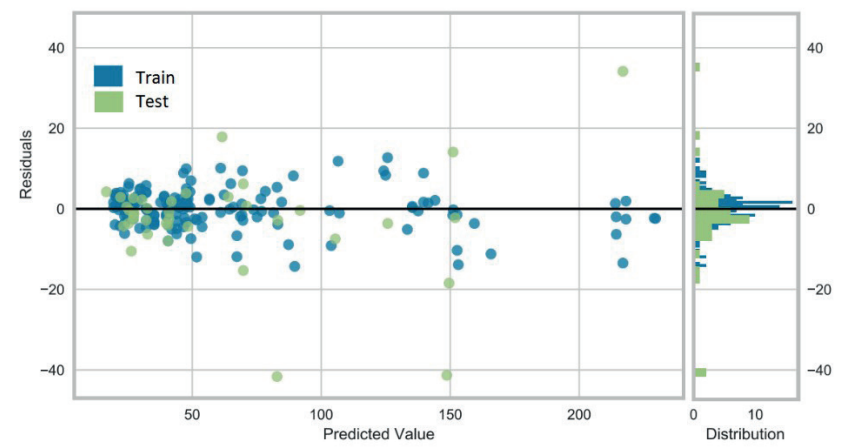

Fig. 9 Residual values in regression analysis for the XGBoost model

\section{References}

[1] El-Sayed, A. K., El-Salakawy, E. F., Benmokrane, B. "Shear strength of FRP-reinforced concrete beams without transverse reinforcement", ACI Materials Journal, 103(2), pp. 235-243, 2006.

[2] Michaluk, C. R., Rizkalla, S. H., Tadros, G., Benmokrane, B. "Flexural behavior of one-way concrete slabs reinforced by fiber reinforced plastic reinforcements", ACI Structural Journal, 95(3), pp. 353-365, 1998.

[3] Razaqpur, A. G., Isgor, B. O., Greenaway, S., Selley, A. "Concrete Contribution to the Shear Resistance of Fiber Reinforced Polymer Reinforced Concrete Members", Journal of Composites for Construction, 8(5), pp. 452-460, 2004. https://doi.org/10.1061/(ASCE)1090-0268(2004)8:5(452)

[4] Tureyen, A. K., Frosch, R. J. "Shear tests of FRP-reinforced concrete beams without stirrups", ACI Structural Journal, 99(4), pp. 427-434, 2002. use of training samples, and alleviate the randomness in selecting test samples. Results of different performance metrics are taken into account. Results show that the extreme gradient boosting framework has successfully predicted the shear strength with a high degree of accuracy and outperforms the other previously developed models. On the other hand, it is inferred that current guidelines provide conservative values of the concrete shear strength of FRP-reinforced concrete beams.

\section{Conflict of interest}

On behalf of all authors, the corresponding author states that there is no conflict of interest.

\section{Nomenclature}

a shear span

$b_{w} \quad$ width of the web

$d$ the effective depth of the cross-section

$E_{c}$ modulus of elasticity of concrete

$f_{c}^{\prime} \quad$ specified compressive strength of concrete

c distance from extreme compression fiber to the neutral axis

$f_{s y} \quad$ yielding strength of the reinforcement

$E_{f}$ modulus of elasticity of flexural FRP reinforcement

$V_{c f}$ nominal shear strength provided by concrete

$\rho_{f}$ reinforcement ratio

$\lambda$ modification factor for the density of concrete

$\beta_{1} \quad$ the depth reduction factor of the equivalent rectangular stress block

[5] Ashour, A. F. "Flexural and shear capacities of concrete beams reinforced with GFRP bars", Construction and Building Materials, 20(10), pp. 1005-1015, 2006.

https://doi.org/10.1016/j.conbuildmat.2005.06.023

[6] Zhang, T., Oehlers, D. J., Visintin, P. "Shear Strength of FRP RC Beams and One-Way Slabs without Stirrups", Journal of Composites for Construction, 18(5), Article number: 04014007, 2014. https://doi.org/10.1061/(ASCE)CC.1943-5614.0000469

[7] Csébfalvi, A., Lógó, J. "Investigation of the possible numerical treatments of a compliance-function-shape-oriented robust truss sizing model with uncertain loading directions", Advances in Engineering Software, 149, Article number: 102899, 2020. https:/doi.org/10.1016/j.advengsoft.2020.102899 
[8] Kaveh, A., Moghanni, R. M., Javadi, S. M. "Ground Motion Record Selection Using Multi-objective Optimization Algorithms: A Comparative Study", Periodica Polytechnica Civil Engineering, 63(3), pp. 812-822, 2019. https://doi.org/10.3311/PPci.14354

[9] Kaveh, A, Javadi, S. M. "Shape and size optimization of trusses with multiple frequency constraints using harmony search and ray optimizer for enhancing the particle swarm optimization algorithm", Acta Mechanica, 225(6), pp. 1595-1605, 2014. https://doi.org/10.1007/s00707-013-1006-Z

[10] Kaveh, A., Moghanni, R. M., Javadi, S. M. "Chaotic optimization algorithm for performance-based optimization design of composite moment frames", Engineering with Computers, 2021. https://doi.org/10.1007/s00366-020-01244-z

[11] Kaveh, A., Dadras Eslamlou, A., Javadi, S. M., Malek, N. G. "Machine learning regression approaches for predicting the ultimate buckling load of variable-stiffness composite cylinders", Acta Mechanica, 232(3), pp. 921-931, 2021.

https://doi.org/10.1007/s00707-020-02878-2

[12] ASCE-ACI Committee 445 on Shear and Torsion "Recent Approaches to Shear Design of Structural Concrete", Journal of Structural Engineering, 124(12), pp. 1375-1417, 1998. https://doi.org/10.1061/(ASCE)0733-9445(1998)124:12(1375)

[13] ACI Committee 440 "Guide for the design and construction of structural concrete reinforced with fiber-reinforced polymer bars", American Concrete Institute, Farmington Hills, MI, USA, ACI PRC-440.1-15, 2015.

[14] CSA "CSA S806-02 Construction of Building Components with Fibre-Reinforced Polymers", Canadian Standards Association, Mississauga, ON, Canada, 2002.

[15] Tureyen, A. K., Frosch, R. J. "Concrete Shear Strength: Another Perspective", ACI Structural Journal, 100(5), pp. 609-615, 2003.

[16] Alam, M. S., Hussein, A. "Unified Shear Design Equation for Concrete Members Reinforced with Fiber-Reinforced Polymer without Stirrups", Journal of Composites for Construction, 17(5), pp. 575-583, 2013.

https://doi.org/10.1061/(ASCE)CC.1943-5614.0000342

[17] Nagasaka, T., Fukuyama, H., Tanigaki, M. "Shear performance of concrete beams reinforced with FRP stirrups", Special publication, 138, pp. 789-812, 1993.

[18] Nakamura, H., Higai, T. "Evaluation of shear strength of concrete beams reinforced with FRP", Doboku Gakkai Ronbunshu, 1995(508), pp. 89-100, 1995. https://doi.org/10.2208/jscej.1995.508_89

[19] Zhao, W., Maruyama, K., Suzuki, H. "Shear behavior of concrete beams reinforced by FRP rods as longitudinal and shear reinforcement", In: 2nd International Symposium, Non-metallic (FRP) Reinforcement for Concrete Structures, Ghent, Belgium, 1995, pp. 352-352.

[20] Duranovic, N., Pilakoutas, K., Waldron, P. "Tests on concrete beams reinforced with glass fibre reinforced plastic bars", In: 3rd International Symposium, Non-metallic (FRP) Reinforcement for Concrete Structures, Sapporo, Japan, 1997, pp. 479-486. [pdf] Available at: http://www.konstrukcija.me/data/OBJAVLJENI_ RADOVI/PDF\%20Format/32.pdf
[21] Swamy, N., Aburawi, M. "Structural implications of using GFRP bars as concrete reinforcement", In: 3rd International Symposium, Non-metallic (FRP) Reinforcement for Concrete Structures, Sapporo, Japan, 1997, pp. 503-510.

[22] Deitz, D. H., Harik, I. E., Gesund, H. "One-way slabs reinforced with glass fiber reinforced polymer reinforcing bars", Special Publication, 188, pp. 279-286, 1999.

[23] Yost, J. R., Gross, S. P., Dinehart, D. W. "Shear Strength of Normal Strength Concrete Beams Reinforced with Deformed GFRP Bars", Journal of Composites for Construction, 5(4), pp. 268-275, 2001. https://doi.org/10.1061/(ASCE)1090-0268(2001)5:4(268)

[24] Alkhrdaji, T., Wideman, M., Belarbi, A., Nanni, A. "Shear strength of GFRP RC beams and slabs", In: Proceedings of the International Conference Composites in Construction - CCC 2001, Porto, Portugal, 2001, pp. 409-414.

[25] Massam, L. "The behaviour of GFRP-reinforced concrete beams in shear", PhD Thesis, University of Toronto, 2001.

[26] Tariq, M., Newhook, J. P. "Shear testing of FRP reinforced concrete without transverse reinforcement", In: Proceedings of the Annual Conference of the Canadian Society for Civil Engineering, Moncton, NB, Canada, 2003, pp. 1330-1339.

[27] Gross, S. P., Yost, J. R., Dinehart, D. W., Svensen, E., Liu, N. "Shear Strength of Normal and High Strength Concrete Beams Reinforced with GFRP Bars", In: International Conference on High Performance Materials in Bridges, Kona, Hawaii, 2003, pp. 426-437. https://doi.org/10.1061/40691(2003)38

[28] El-Sayed, A., El-Salakawy, E., Benmokrane, B. "Shear Strength of One-Way Concrete Slabs Reinforced with Fiber-Reinforced Polymer Composite Bars", Journal of Composites for Construction, 9(2), pp. 147-157, 2005. https://doi.org/10.1061/(ASCE)1090-0268(2005)9:2(147)

[29] El-Sayed, A. K., El-Salakawy, E. F., Benmokrane, B. "Shear capacity of high-strength concrete beams reinforced with FRP bars", ACI Materials Journal, 103(3), pp. 383-389, 2006.

[30] Guadagnini, M., Pilakoutas, K., Waldron, P. "Shear Resistance of FRP RC Beams: Experimental Study", Journal of Composites for Construction, 10(6), pp. 464-473, 2006. https://doi.org/10.1061/(ASCE)1090-0268(2006)10:6(464)

[31] Matta, F., Nanni, A., Hernandez, T. M., Benmokrane, B. "Scaling of strength of FRP reinforced concrete beams without shear reinforcement", In: Fourth International Conference on FRP Composites in Civil Engineering (CICE2008), Zurich, Switzerland, 2008, pp. 1-6.

[32] Jang, H., Kim, M., Cho, J., Kim, C. "Concrete shear strength of beams reinforced with FRP bars according to flexural reinforcement ratio and shear span to depth ratio", presented at the 9th International Symposium on Fiber Reinforced Polymer Reinforcement for Concrete Structures, Sydney, Australia, July, 13-15, 2009.

[33] Bentz, E. C., Massam, L., Collins, M. P. "Shear Strength of Large Concrete Members with FRP Reinforcement", Journal of Composites for Construction, 14(6), pp. 637-646, 2010. https://doi.org/10.1061/(ASCE)CC.1943-5614.0000108

[34] Olivito, R. S., Zuccarello, F. A. "On the Shear Behaviour of Concrete Beams Reinforced by Carbon Fibre-Reinforced Polymer Bars: An Experimental Investigation by Means of Acoustic Emission Technique", Strain, 46(5), pp. 470-481, 2010. https://doi.org/10.1111/j.1475-1305.2009.00699.x 
[35] Abed, F., El-Chabib, H., AlHamaydeh, M. "Shear characteristics of GFRP-reinforced concrete deep beams without web reinforcement", Journal of Reinforced Plastics and Composites, 31(16), pp. 10631073, 2012.

https://doi.org/10.1177/0731684412450350

[36] Matta, F., El-Sayed, A. K., Nanni, A., Benmokrane, B. "Size Effect on Concrete Shear Strength in Beams Reinforced with FiberReinforced Polymer Bars", ACI Structural Journal, 110(4), pp. 617628, 2013.

[37] Tibshirani, R. "Regression Shrinkage and Selection Via the Lasso", Journal of the Royal Statistical Society: Series B (Methodological), 58(1), pp. 267-288, 1996.

https://doi.org/10.1111/j.2517-6161.1996.tb02080.x
[38] Breiman, L. "Random Forests", Machine Learning, 45(1), pp. 5-32, 2001.

https://doi.org/10.1023/A:1010933404324

[39] Chen, T., Guestrin, C. "XGBoost: A Scalable Tree Boosting System", In: Proceedings of the 22nd ACM SIGKDD International Conference on Knowledge Discovery and Data Mining, San Francisco, CA, USA, 2016, pp. 785-794. https://doi.org/10.1145/2939672.2939785

[40] Kohavi, R. "A study of cross-validation and bootstrap for accuracy estimation and model selection", In: Proceedings of the 14th International Joint Conference on Artificial Intelligence (IJCAI), Montreal, QC, Canada, 1995, pp. 1137-1145. 